\title{
What Do Philosophers Do? Maddy, Moore and Wittgenstein
}

\author{
Annalisa Coliva \\ University of California, Irvine \\ a.coliva@uci.edu
}

\begin{abstract}
The paper discusses and presents an alternative interpretation to Penelope Maddy's reading of G.E. Moore's and Ludwig Wittgenstein's anti-skeptical strategies as proposed in her book What Do Philosophers Do? Skepticism and the Practice of Philosophy. It connects this discussion with the methodological claims Maddy puts forward and offers an alternative to her therapeutic reading of Wittgenstein's On Certainty.
\end{abstract}

\section{Keywords}

G.E. Moore - Ludwig Wittgenstein - skepticism - common sense - therapy - metaphilosophy

\section{$1 \quad$ Introduction}

It is a great honor for me to have been invited to participate in this symposium on Penelope Maddy's book with such distinguished colleagues. Indeed, Maddy and Barry Stroud have been two of my philosophical heroes since I started being interested in analytic philosophy over twenty years ago. Stroud's book, The Significance of Philosophical Scepticism (1984), was inspirational and shaped my philosophical interests ever since I read it. Maddy's work on the philosophy of mathematics, naturalism and the takehome message of Wittgenstein's reflections on The Logical Must (Maddy 
2014) has always been an important source of inspiration for my own work and thinking on these issues. I would also like to thank Adam Leite for inviting me to participate in the symposium and for being such a stimulating philosophical interlocutor over the years.

What Do Philosophers Do? Skepticism and the Practice of Philosophy is an incredibly original and thought-provoking book. It is also an extremely ambitious piece of work, since it knits together two of the hardest topics in philosophy-i.e. skepticism and meta-philosophy. And it does so admirably, with a clear and approachable style.

In my comments, I would like to concentrate on Chapter 3 of the book. But before delving into more specific comments, let me just offer a brief overview of that chapter and of what I will be arguing for.

\section{$2 \quad$ Overview}

Chapter 3 focuses on the philosophy of common sense, particularly on G.E. Moore and on Wittgenstein. Maddy thinks highly of Moore's strategy, which is much more subtle than what meets the eye. In fact, as she reconstructs it, it depends on insisting, contra a skeptic or a philosopher moved by skepticism, that one can know things, such as that there is a hand here, and that there is another one there, even if one cannot prove that, because one cannot prove one is not dreaming. Furthermore, Moore's strategy consists in pointing out that he has perfectly good evidence of being awake and yet this evidence would not satisfy the opponent, since the latter is concerned with "extraordinary dreaming" (2017: 31) rather than ordinary dreaming. Yet, according to Maddy, the moral of Moore's Proof seems to be that following the opponent on the demand of being able to exclude extraordinary dreaming to grant knowledge is misguided.

I will raise some questions with respect to this reconstruction of Moore's strategy, although there is much I agree with Maddy on that.

In the same chapter, she proposes a novel-therapeutic-interpretation of Wittgenstein's On Certainty. If I understood her correctly, contrary to socalled 'framework' readings of On Certainty, Maddy thinks that Wittgenstein was not proposing any positive view, or theory, concerning "hinge propositions," but merely aimed at re-habilitating common sense, or perhaps better, the ordinary use of 'know', even in connection with hinge propositions. In this sense, he was much closer to Moore than he thought and in fact much of his critique of Moore was based on a misunderstanding of what the latter was really after. 
Here is probably where Maddy and I are more in disagreement. Not because I think Wittgenstein was proposing a theory of hinges, but because I think there is good evidence to claim that he was not in favor of rehabilitating the ordinary use of 'know' with respect to hinges, at all. Rather, he thought that under the superficial similarity, the use of 'I know' with respect to hinges had to be taken to be "grammatical" (OC 58 ) and thus not as stating an epistemic relation obtaining between a subject and a proposition (or a fact), but as expressing something else.

Finally, the chapter closes with a comparison between science and math on the one hand, and philosophy on the other. According to Maddy, math and science target imprecise theoretical concepts, which are then refined in the light of extensive knowledge of the relevant field of inquiry. Fruitfulness with respect to criteria internal to the discipline is the meter of success in math, while in the empirical sciences it is the removal of apparent contradictions between theory and empirical findings.

Philosophy, in contrast, targets everyday concepts. The methodology usually consists in proposing a set of necessary and sufficient conditions, in raising counter-examples, and then in refining those conditions until no false positives or negatives emerge. The criterion of success is to track phenomena or an essence that those concepts supposedly refer to. Maddy is very skeptical of this methodology and recommends engaging in more ordinary language investigations and in therapeutic and also more naturalist-oriented philosophy.

Here I am very much in agreement with Maddy on her description and evaluation. However, I am generally less inclined towards naturalism than she is, and I would insist that a systematic, yet pluralistic philosophy could still be pursued, once it is realized that there is no essence of, say, truth, knowledge or justification to be investigated with particularly powerful spectacles that only philosophers would allegedly possess.

\section{$3 \quad$ Moore}

As anticipated, there is a lot I agree with in Maddy's reconstruction of Moore. Indeed, I have defended a very similar reading in print. However, I have also been puzzled by several things Moore did say, which do not obviously square with it. Let me explain.

In his “Reply to My Critics," Moore unequivocally claims:

I have sometimes distinguished between two different propositions, 
each of which has been made by some philosophers, namely (1) the proposition 'There are no material things' and (2) the proposition 'Nobody knows for certain [my italics] that there are any material things'. And in ... "Proof of an External World" (...) I implied with regard to the first of these propositions that it could be proved to be false in such a way as this; namely, by holding up one of your hands and saying 'This hand is a material thing; therefore there is at least one material thing'. But with regard to the second of these propositions, which has, I think, been far more commonly asserted than the first, I do not think I ever implied that it could be proved to be false in any such simple way (...).

MOORE 1942: 668

So Moore did not think of his proof as an anti-skeptical one. His target was idealism, not skepticism. And in the "Proof of the External World" itself he candidly admitted that addressing skepticism would require proving the premises of his proof. That, in turn, would require proving that he wasn't dreaming and he admitted not to be able to do it. Here is the passage:

How am I to prove now that 'Here is one hand, and here's another?' I do not believe I can do it. In order to do it, I should need to prove for one thing, as Descartes pointed out, that I am not now dreaming. But how can I prove that I am not? I have, no doubt, conclusive reasons for asserting that I am not now dreaming; I have conclusive evidence that I am awake: but that is a very different thing from being able to prove it.

MOORE 1939: 150

Notice that here Moore is not objecting to the Cartesian challenge-that is, the challenge of proving that he isn't dreaming. On the contrary, he is saying that if he had to give a proof of his premises he should answer that challenge. Since, fortunately, he does not have to give a proof of his premises, since he is not addressing skepticism but idealism, he can avoid addressing it. Notice, furthermore, that he is not attempting to demote the challenge. That is, he is perfectly aware that that challenge involves "extraordinary dreaming," as Maddy (2017: 31) calls it, rather than ordinary dreaming. And yet he is not saying anything against its legitimacy.

Now, we do know that in later writings, particularly "Certainty" and "Four Forms of Scepticism," he revisited the Cartesian challenge and proposed 
what is known as Moore's gambit, as well as considerations in favor of the greater rationality of sticking to our ordinary beliefs. Yet we also know he was not happy with these writings, which only appeared posthumously. Nevertheless, he also says in "Proof of an External World" (Moore 1939: 150) that he knows things which he cannot prove, such as the premises of his proof.

So the Cartesian challenge is intelligible, legitimate, and unanswerable, for Moore. Yet, it does not impugn knowledge of ordinary truths such as "Here is my hand" because - in a proto-externalist spirit—Moore is advancing the idea that knowledge does not entail proof of one's knowledge or being able to show how or that one knows.

Thus, Moore is not just insisting that common sense has it right and Descartes has it wrong, in the sense of raising a challenge which is somewhat misguided or irrelevant, once one is deeply and healthily rooted in common sense. Rather, he is making a typically epistemological move of denying the underlying principle on which the Cartesian challenge-as unanswerable as it is-would jeopardize ordinary knowledge. That is, through the endorsement of the famous (or infamous) KK principle:

$$
(\mathrm{KK}) \mathrm{K} \rightarrow \mathrm{KK}
$$

For that principle is key to going from

(1) If one cannot prove one is not dreaming, one cannot prove to know that $\mathrm{P}$ (e.g. "Here is a hand"),

which Moore, as we have just seen, does grant, to

(2) One does not know that there is a hand here (via contraposition \& KK).

Some motivation for denying KK does come from considering common sense superior to any other philosophical pretension or request. But that very move could be defended, and has been defended differently after all (for instance, by appealing to cases like those of children and the unsophisticated to show how $\mathrm{K}$ does not entail $\mathrm{KK}$ ).

I am not convinced this move is ultimately decisive against skepticism, since a skeptic could either reject its legitimacy, or, in a less question-begging way, insist on the second-order challenge that she could still raise and that would go unanswered by Moore's lights. That is, a skeptic could grant 
knowledge of ordinary empirical propositions and yet ask the opponent to be able to claim or to prove it. Indeed, it seems to me that Moore himself, for all we have seen so far, understood the skeptical challenge that way: not as targeting knowledge of "Here is a hand" per se, but our right to claim itwhence the insistence that he was confronting idealism, not skepticism; that he knew his premises and therefore the conclusion of his argument; and, yet, that to address skepticism he should have proved his premises.

Be that as it may, it is clear that Moore, as Maddy rightly remarks, is not just a Plain Man. He is a philosopher, who makes very interesting and quite sophisticated moves, even when their motivation comes from an alignment with common sense. It is also clear that he is totally cognizant of the Cartesian skeptical challenge, which he takes seriously and in its full complexity, even if, thanks to his proto-externalism, he is able to defuse some - not all —of its devastating consequences, by making knowledge of ordinary propositions, like "Here is my hand," immune to it.

\section{$4 \quad$ Wittgenstein and What Philosophers Should Do}

I agree with Maddy that Wittgenstein was pursuing largely therapeutic ends in his later writings, including On Certainty. We disagree, I think, on the scope and the results of this therapy. In my reading of Wittgenstein's $O n$ Certainty, he was equally critical of skepticism and of Moore. He objected to the former by insisting that he would transgress the boundaries of sense by raising doubts which would be global (or "from scratch," as Maddy (2017:37) calls them); that would not make any difference in practice; that would not be based on grounds but merely on conceivable hypotheses at best; that would not belong to any of our ordinary empirical inquiries within which legitimate doubts can arise and may possibly be solved by appealing to various kinds of evidence, thanks to taking many things for granted. ${ }^{1} \mathrm{He}$ also objected to the intelligibility of the hypothesis from dreaming, by arguing that if we were to dream it, we would not be using meaningful words (OC 383 ), after all, since their employment would be completely severed from the ordinary circumstances which solely provide the criteria for their meaningful employment. Thus, the hypothesis from dreaming is either self-defeating, because, if we were dreaming, we would be dreaming of it, and our words

\footnotetext{
${ }^{1}$ For a more detailed analysis of all these objections, see Coliva (2010: Ch. 3).
} 
would only retain an appearance of meaning; or else it is false, if we are not in fact dreaming and are actually entertaining it. $^{2}$

Although I myself would not espouse this anti-skeptical strategy, ${ }^{3}$ it seems very much in keeping with the kind of analysis of ordinary language Maddy seems to be keen on. Yet, the analysis extends beyond language to ordinary and scientific epistemic practices, and-yes-it involves recognizing that these practices rest on ungrounded presuppositions. Yet, those presuppositions are of the essence of those very practices (OC 341-344). This is indeed a kind of discovery - even though certainly not a theory - we make, according to Wittgenstein, by paying attention to the "logic," as he calls it, of our empirical and scientific investigations.

However, Wittgenstein also objected to Moore's use of 'I know' in connection with his truisms and the premises of his proof, on the grounds that he would not have reasons in support of his claims to knowledge; and that in fact he would have no reasons stronger than what they were supposed to ground; or that no investigation could be legitimately be carried out to establish that things are as he claimed them to be; that his use of 'I know' would not be relevant in the communicative context at hand; and, finally, that in that kind of context, it would not make sense to doubt or to deny that one knows. ${ }^{4}$ Thus, Wittgenstein was against Moore the philosopher of common sense and his use of 'I know', as much as he was against the skeptic and his use of 'to doubt'.

Yet, he also put forward the view that with respect to Moore's truisms, and the premises of his proof, as well as many other hinge propositions, the use we may make of 'I know' in our ordinary language would actually be "grammatical" (OC 58). So we-Plain Men and Women-do use 'I know' in connection with those propositions. Yet, despite the identical linguistic form, those words do not mean the same as 'I know' in "I know that my kids are at

2 The similarity between Wittgenstein's anti-Cartesian strategy in On Certainty (1969) and Putnam's in "Brains in a Vat" (1981) is striking. I have not been able to find any evidence, however, that Putnam was inspired by the reading of On Certainty. Putnam does mention Wittgenstein in his celebrated paper, but only the Wittgenstein of the Philosophical Investigations (1953), in connection with the idea that signs by themselves (and even mental images) do not mean anything, even when they resemble their alleged references. He also mentions the relevance of this Wittgensteinian idea to his own work on the LöwenheimSkolem theorem, but he refers only to the Philosophical Investigations.

${ }^{3}$ I have developed an alternative anti-skeptical strategy in Coliva (2015).

${ }^{4}$ For a more detailed analysis of all these objections, see Coliva (2010: Ch. 2). 
home right now," based on my husband's testimony over the phone a few minutes ago, together with hearing them speak on the phone and reporting being there. As Wittgenstein puts it, in the grammatical use of 'I know', the 'I' is unimportant, because that claim concerns things that everyone would 'know' (as long as they are normal adult human beings, as Moore himself noticed in "A Defence of Common Sense"); it expresses objective certaintythat is to say, the impossibility of doubt or of being wrong - not due to some form of individualistic certainty or privileged access, but due to the peculiar role that the propositions thereby 'known' play within our language games and epistemic practices.

So, yes, Wittgenstein, as Maddy observes, would not object to an ordinary person saying that they 'know' that the Earth has existed for a very long time (OC 407). But not because that person, contrary to Moore, has the right to claim knowledge with respect to that hinge. (Why use a double standard like that?) Rather, because, as Wittgenstein puts it "I feel (rightly?) that these two mean to say something different" (OC 407). For Moore wants to lay claim to knowledge, whereas the ordinary person expresses their certainty, through those very same words. Such certainty is not due to philosophical scrutiny, but to their being brought up in a community that share that as a presupposition of countless language games and epistemic practices. Indeed, Wittgenstein recommends disambiguating and substituting the "grammatical" occurrences of 'I know' with "it stands fast for me and many others..." (OC 116, feststehen is the verb he proposes substituting for wissen).

My claim is that Wittgenstein's aim, contrary to Moore's, was not that of defending common sense, but of making sense of common sense, by revealing the multiplicity behind the apparent uniformity: in this particular case, the multiplicity of what 'I know' could actually mean, despite the uniformity of those very words across very different uses. Or again, the multiplicity of roles and functions propositions can have, despite their superficial similarity - that is, despite their being propositions of the form of empirical ones, and despite their being propositions (in most cases) about empirical objects. Thus, although Wittgenstein too, like Moore, is certainly not against common sense, he also thinks that what passes as common sense is not self-explanatory or obvious, and therefore true, known and certain (as Moore thought of his truisms in "A Defence of Common Sense"). The aim of philosophy, therefore, is not that of defending it as such, or of utilizing it, as such, against opposite philosophical claims. The aim of philosophy, for Wittgenstein, is not even simply that of describing it, as if everything was already open to the view and clear and manifest as such. Rather, it is that of offering a "perspicuous (re)presentation" of it (PI 122, übersichtlichen 
Darstellung), and this may involve going beyond simplistic views which seem to be deposited within it (like that I know that the Earth has existed for a very long time, just as I know that my kids are at home now; or that those two propositions play the same role in our language games and epistemic practices). As Maddy quotes Wittgenstein:

The aspects of things that are most important for us are hidden because of their simplicity and familiarity. (One is unable to notice somethingbecause it is always before one's eyes.) The real foundations of the inquiry do not strike people at all. (PI 129)

So something is hidden, after all, for Wittgenstein (or, if not hidden, at least blurred); and it takes a lot of philosophical acumen to see it and to see it right. Neither a skeptic, nor Moore, or indeed the Plain Man do possess that acumen, according to him. Something is hidden and yet it is already there to be seen by eyes whose powers are not blurred when directed at things that are at close distance. Being against theory, as Wittgenstein certainly was, even in On Certainty, does not mean to be averse to the idea that philosophy can actually discover something: not causes, not essences, but multiplicity behind uniformity. And to pursue therapy does not mean going back to a state of nature (or of 'second nature'). This, as Maddy rightly says, would strike many as "a crimped view of the philosophical project" (Maddy 2017: 200) —no philosophy unless one gets ill, and philosophical therapy imposed only to go back to where we were before catching the disease. It means, rather, to cure the kind of intellectual cramp that does not allow us to see things aright. This is a cramp we have as Plain People and that many philosophers have not got rid of, according to Wittgenstein. And that is what needs to be cured, in his view.

And yet, to go back to Maddy's claims about what philosophers do, or in fact should do: it seems to me that Wittgenstein is at least as good as Austin - whom Maddy greatly admires - at revealing the multiplicity lying behind the uniformity of our words and at using that finding for strongly anti-metaphysical purposes. Indeed, it is Wittgenstein, to my mind, that made the most to make us aware of the folly of thinking that philosophers are just like scientists, yet endowed of super powerful telescopes (or microscopes, depending on how you want to go about it), which allow them to investigate essences which our concepts are allegedly tracking. For those essences disappear once we start paying attention to the diversity of actual and concrete uses of words and, thus, become aware of the diversity and multiplicity of their meanings. 
This kind of lesson is not just of historical interest, to me. Pluralistic projects are currently underway in philosophy and seem highly valuable to me. I have in mind the copious studies on various kinds of pluralism, such as alethic, logical, epistemic pluralism, or indeed on pluralism about selfknowledge. Yet, this is not the place to elaborate on that.

\section{$5 \quad$ Conclusion}

I hope that the preceding has made clear the extent of my admiration for Maddy's wonderfully rich and thought-provoking book. Although, as the saying goes, the devil is in the details, I would insist that our disagreements are local and that they should not in any way obscure the vast agreement we have on the broader picture. That is, on the interest of skepticism and of its relationship with common sense, on the importance of Moore and Wittgenstein, on several aspects of Moore's strategy, on the significance-for philosophy — of the scientific study of vision, ${ }^{5}$ on the aim of philosophy, and on what philosophers do, or should do, which is certainly not either old style conceptual analysis, or, as Maddy calls it (2017: 214), "Gettierology."

\section{References}

Coliva, A. 2010. Moore and Wittgenstein: Scepticism, Certainty and Common Sense. London: Palgrave.

Coliva, A. 2015. Extended Rationality: A Hinge Epistemology. London: Palgrave.

Maddy, P. 2014. The Logical Must: Wittgenstein on Logic. Oxford: Oxford University Press.

Maddy, P. 2017. What Do Philosophers Do? Skepticism and the Practice of Philosophy. Oxford: Oxford University Press.

Moore, G.E. 1939. "Proof of an External World." In his Collected Papers, 126-148. London: Allen and Unwin.

Moore, G.E. 1942. "A Reply to My Critics." In P.A. Schillp (ed.), The Philosophy of G.E. Moore, 535-677. Chicago: Northwestern University Press.

Putnam, H. 1981. "Brains in a Vat." In his Reason, Truth and History, 1-21. Cambridge:

${ }^{5}$ For reasons of space, I could not comment on the rich discussion of the argument from illusion in Chapter 2 of What Do Philosophers Do? 
Cambridge University Press.

Stroud, B. 1984. The Significance of Philosophical Scepticism. Oxford: Oxford University Press.

Wittgenstein, L. 1953. Philosophical Investigations. Oxford: Blackwell.

Wittgenstein, L. 1969. On Certainty. Oxford: Blackwell. 